\title{
Microvasculature of the Lingual Papillae of the Common Opossum (Didelphis marsupialis)
}

\author{
Shigenori Okada Dean E. Schraufnagel
}

Department of Medicine M/C 719, University of Illinois at Chicago, 840 S. Wood St. Chicago, IL 60612-7323, USA.

The mammalian tongue has undergone extensive adaptation for highly specialized functions in different species. Its study, along with other anatomical structures, can give important information about an animal's habits and diet. This information may also show taxonomic relationships. Sonntag [1][2][3] described the macroscopic features and histology of many mammals with light microscopy. He found that the tongue varied with habit, diet, adaptation, and phylogeny. Several other investigators [4][5][6] later described the lingual characteristics that helped determine the taxonomy and phylogeny of different mammals.

The opossum has 4 kinds of lingual papillae (filiform, conical, fungiform, vallate). Scanning electron microscopy of the external features, connective tissue cores, and corrosion casts of the microvasculature show the filiform papillae have a spearhead-like main process and spiny accessory processes around the apical part of the main process. The shape and number of both processes depend on their position on the tongue. On the apex, the main processes have shovel-like capillary networks and the accessory processes have small conical networks. On the lingual radix, the processes have small capillary loops. In the patch region, conical papillae have capillaries arranged as a full sail curving posteriorly (Figure 1 and 2). The fungiform papillae are scattered among the filiform papillae and have capillary baskets beneath each taste bud. Giant fungiform papillae on the tongue tip are 3 to 4 times larger than the ones on the lingual body. Capillaries of giant papillae form a fan-shaped network. The opossum has 3 vallate papillae arranged in a triangle. Their tops have secondary capillary loops but not their lateral surfaces. Mucosal folds on the posterolateral border have irregular, finger-like projections with cylindrical capillary networks.

These findings and the structure of the rest of the masticatory apparatus suggest the lingual papillae of opossum have kept their ancestral carnivorous features but also developed the herbivore characteristics of other marsupials.

\section{References}

[1] Sonntag, C.F. (1923). The comparative anatomy of the tongues of the mammalia. VIII. Carnivora. Proc. Zool. Soc. Lond. 129-152.

[2] Sonntag, C.F. (1924). The comparative anatomy of the tongues of the mammalia. XI. Marsupialia and Monotremata. Proc. Zool. Soc. Lond. 743-755.

[3] Sonntag, C.F. (1925). The comparative anatomy of the tongues of the mammalia. XII. Summary, classification and phylogeny. Proc. Zool. Soc. Lond. 701-762.

[4] Fish, H.S., Malone, P.D., Richter, C.P. (1944). The anatomy of the tongue of domestic Norway rat. Anat. Rec. 89:429-440.

[5] Kutuzov, H., Sicher, H. (1951). The filiform and the conical papillae of the papillae of the tongue in the white rat. Anat. Rec. 110:275-288.

[6] Livingston, R.M. (1956). Some observation on the natural history of the tongue. Ann. Roy. Coll. Surg. Engl. 19:185-200. 

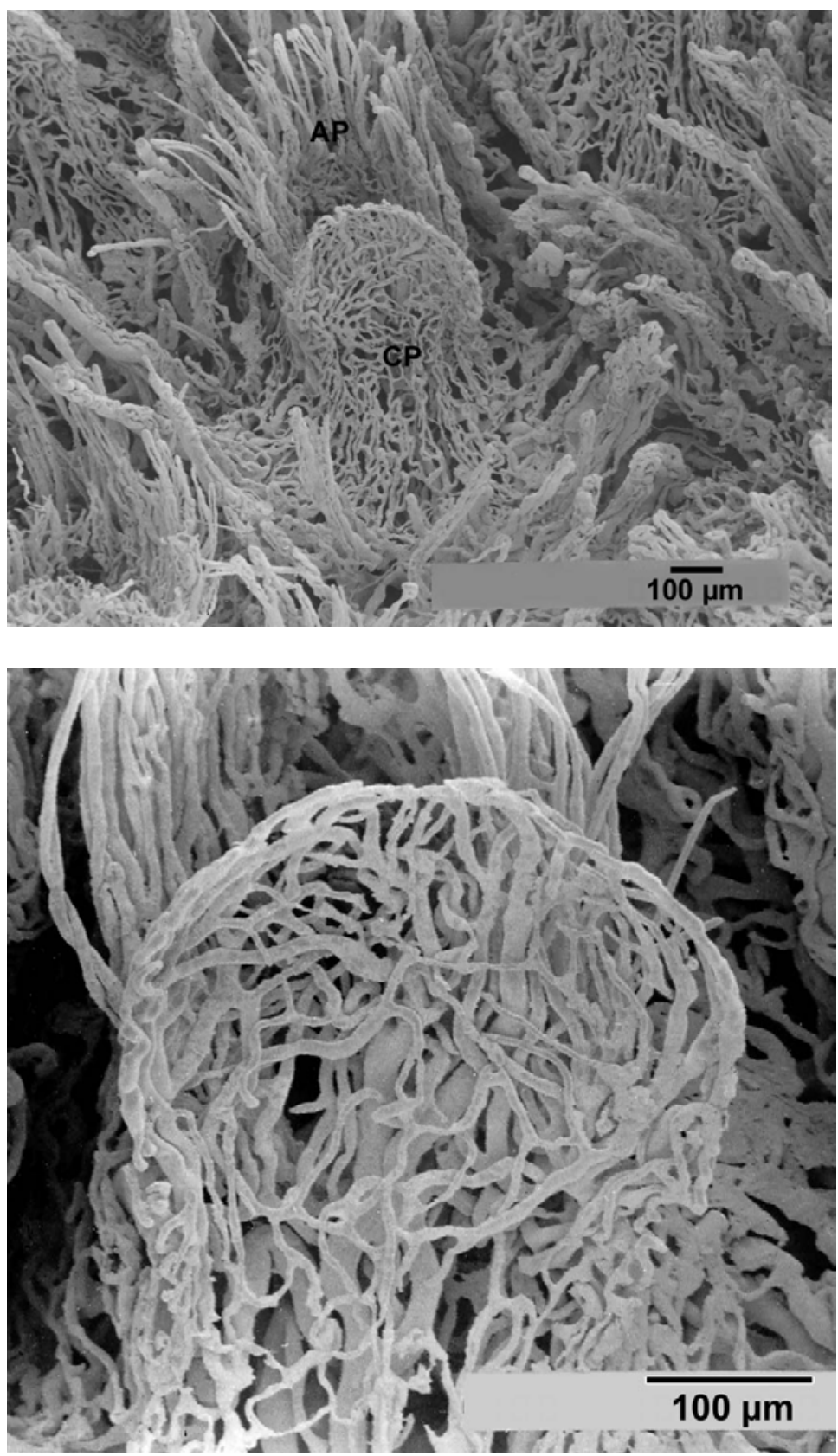

Figure 1. Scanning electron micrograph of a microvascular cast of a conical papilla $(\mathrm{CP})$ in the patch. The giant conical process is supplied by a round capillary network that appears as a full sail curving posteriorly. Shorter accessory processes (AP) are seen anteriorly. These processes get longer as they go posteriorly.

Figure 2 is a close-up view of the cast capillaries of the main process of a conical papilla. It is much larger than any other lingual papilla and always points posteriorly. The capillaries of the conical capillary network also supply the accessory processes. 